\title{
The Histopathological Changes after Neoadjuvant Theraphy for Rectal Carcinoma
}

\author{
Omer Faruk Ozkan ${ }^{1}$, Nuri Emrah Goret ${ }^{2}$ and Ceren Canbey Goret ${ }^{3 *}$ \\ ${ }^{1}$ Department of General Surgery, Health Sciences University, Umraniye Research and Education Hospital, Istanbul, Turkey \\ ${ }^{2}$ Department of General Surgery, Health Sciences University, Kartal Dr Lütfi Kirdar Research and Education Hospital, Istanbul, Turkey
}

${ }^{3}$ Department of Surgical Pathology, Health Sciences University, Sancaktepe Research and Education Hospital, Istanbul, Turkey

Received: 輩August 05, 2018; Published: August 09, 2018

*Corresponding author: Ceren Canbey Goret, MD Health Sciences University, Sancaktepe Research and Education Hospital, Department of Surgical Pathology, Floor 0, Istanbul, Turkey

\begin{abstract}
Colorectal carcinomas are the third most common carcinomas in men and the second most common carcinomas in women. It has also been reported that deaths due to colorectal cancers account for approximately $9 \%$ of all cancer mortalities. Because chemotherapy, radiotherapy and/or neoadjuvant chemoradiotherapy are potentially beneficial during the preoperative period in terms of local control and sphincter-preserving surgery, they are particularly recommended for advanced stage carcinomas. With changing oncological treatments, care should be taken to ensure that the pathological staging of these cases are diligently and correctly performed, and pathological changes that may be present in the tumour after neoadjuvant therapy and staging systems have to be known.
\end{abstract}

Keywords: Low Anterior Resection; Abdominoperineal Resection; Colorectal Carcinoma; Total Mesorectal Excision; Neoadjuvant Therapy

\section{The Histopathological Changes after Neoadjuvant} Theraphy for Rectal Carcinoma

Colorectal carcinomas are the third most common carcinomas in men and the second most common carcinomas in women [1]. A study conducted in 2014 has reported that there are approximately 10,000 new colon cancer cases and nearly 40,000 new rectal carcinoma cases in the United States. It has also been reported that deaths due to colorectal cancers account for approximately $9 \%$ of all cancer mortalities [2]. Because chemotherapy, radiotherapy and/or neoadjuvant chemoradiotherapy are potentially beneficial during the preoperative period in terms of local control and sphincter-preserving surgery, they are particularly recommended for advanced stage carcinomas [3]. According to the current guidelines, neoadjuvant therapy is recommended for all stage T3 rectal carcinomas extending from the muscularis propria to the perirectal fatty tissue, with lymph node or distant metastasis [4].

For the evaluation of the presence or absence of stage and lymph node metastasis during the preoperative period, endorectal ultrasound and pelvic MRI are recommended [3]. In the literature, it is mentioned that chemotherapy and radiotherapy should be simultaneously performed for rectal carcinomas, and after the neoadjuvant treatment, an observational approach in the "wait and see before operation" approach should be adopted [5]. Although this approach has been recently proposed, a definite diagnosis of the presence of residual tumour in the rectum can be made only after a histopathological examination. We believe that this "wait and see before operation" approach will be increasingly adopted as information on the treatment protocols is applied, and the final histopathological diagnosis and regression grades of operated cases are more commonly reported in the literature.

Low anterior resection (sphincter-preserving surgery) is preferred after neoadjuvant therapy if there is tumour regression, particularly in lower rectal tumours, in terms of patient comfort and convenient surgical intervention or in some cases instead of abdominoperineal resection by performing intraoperative consultation (frozen section) of rectum distal surgical margin. With changing oncological treatments, care should be taken to ensure that the pathological staging of these cases are diligently and correctly performed, and pathological changes that may be present in the tumour after neoadjuvant therapy and staging systems have to be known. There are several classification systems 
in terms of pathological staging when evaluating specimens after neoadjuvant therapy. In terms of the ease of evaluation and creating a shared convenience with clinicians, we usually evaluate our cases according to the 4-level staging system of Dworak and Rödel (Tables $1 \& 2)[6,7]$.

Table 1: Dworak's regression grading system (6)

\begin{tabular}{|c|c|}
\hline Grade 0 & no regression \\
\hline Grade 1 & $\begin{array}{l}\text { minor regression (dominant tumor mass with obvious } \\
\text { fibrosis) }\end{array}$ \\
\hline Grade 2 & $\begin{array}{l}\text { moderate regression (dominant tumor mass with } \\
\text { obvious fibrosis) }\end{array}$ \\
\hline Grade 3 & $\begin{array}{c}\text { good regression (dominant fibrosis outgrowing the } \\
\text { tumor mass) }\end{array}$ \\
\hline Grade 4 & $\begin{array}{c}\text { total regression (no viable tumor cells, only fibrotic } \\
\text { mass) }\end{array}$ \\
\hline
\end{tabular}

Table 2: Rödel's regression grading system (7)

\begin{tabular}{|c|c|}
\hline TRG 0 & No regression \\
\hline TRG 1 & $\begin{array}{c}\text { Minor regression, fibrosis in only 25\% or less of the tumor } \\
\text { mass }\end{array}$ \\
\hline TRG 2 & $\begin{array}{c}\text { Dominant tumor mass with obvious fibrosis in } 26 \% \text { to } 50 \% \\
\text { of the tumor mass }\end{array}$ \\
\hline TRG 3 & $\begin{array}{c}\text { Dominant fibrosis outgrowing the tumor mass (ie, more than } \\
50 \% \text { tumor regression) }\end{array}$ \\
\hline TRG4 & Total regression, no viable tumor cells, only fibrotic mass \\
\hline
\end{tabular}

*TGR: Tumor regression grade

\section{Following Neoadjuvant Treatment}

Macroscopically, sometimes the tumour is completely regressed and tumour mass may not be seen. Mucosal flattening, mild ulcerlike areas, or bright areas due to possible mucinous pools can be seen in the old tumour area (Figure 1). Histopathologically, fibrosis is at the forefront of common changes that require attention. We present the grading system primarily by comparing fibrosis and tumour rates. Histopathological changes other than fibrosis include nuclear pleomorphism, cytoplasmic vacuolation and mucine pools [8-10]. Another important aspect of rectum specimens receiving neoadjuvant treatment is the assessment of lymph node. If there is a metastatic lymph node, then morphological changes similar to tumour regression will be observed in these nodes. Regression may develop in the regional lymph nodes in these cases receiving combined chemoradiotherapy, and secondary lymph nodes may not be detected. As the dissection of the lymph node becomes more difficult in such cases, it should be meticulously performed and methods for removing the mesorectal adipose tissue, such as methylene blue assisted lymph node dissection or acetone compression, may be performed when necessary as reported in the literature [11-14]. In our clinic, after performing necessary macroscopic sampling procedures for the tumour, we keep the mesorectal fat tissue portion overnight in alcohol, melt and harden the fat and sample a large part or sometimes all of the remaining fat tissues.

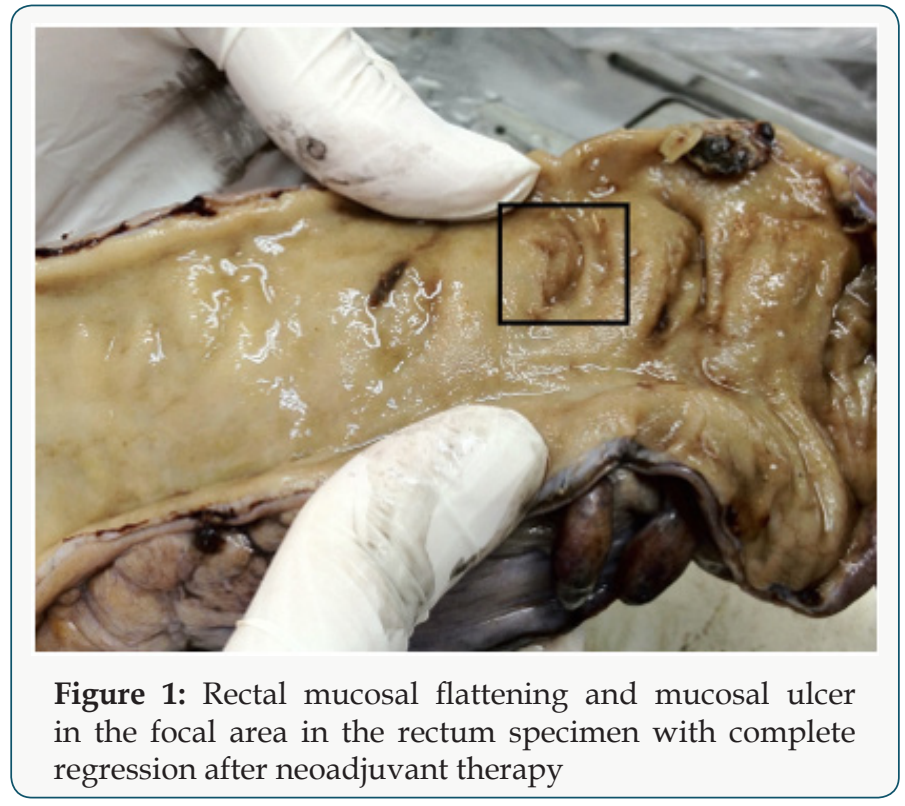

\section{Conclusion}

a) Before the pathologic sampling of the specimen is performed, it is necessary to report to the pathologist whether the patient is treated using neoadjuvant therapy.

b) In the evaluation of rectal carcinoma cases, a pathological evaluation, which is one of the most fundamental pillars, should be carefully and diligently performed. Each pathologic parameter should be carefully evaluated and the tumour regression grade should be reported.

c) In these cases, the clinician and pathologist must work in a collaborative manner.

\section{References}

1. Resch A, Schneider NI, Langner C (2015) Pathological evaluation of colorectal cancer specimens: advanced and early lesions. Cesk Patol 51(1): 12-22.

2. Siegel R, Ma J, Zou Z, Jemal A (2014) Cancer statistics,2014. CA Cancer J Clin 64(1): 9-29

3. Wang XT, Li DG, Li L, Kong FB, Pang LM, et al. (2015) Meta-analysis of oncological outcome after abdominoperineal resection or low anterior resection for lower rectal cancer. Pathol Oncol Res 21(1): 19-27.

4. Leeds IL, Fang SH (2018) Neoadjuvant Therapy for Rectal Cancer. Dis Colon Rectum 61(8): 883-886.

5. Willett CG (2018) Management of Locoregional Rectal Cancer. J Natl Compr Canc Netw 16(5S): 617-619.

6. Dworak O, Keilholz L, Hoffmann A (1997) Pathological features of rectal cancer after preoperative radiochemotherapy. Int J Colorectal Dis 12(1): 19-2310.

7. Rödel C, Martus P, Papadoupolos T, Füzesi L, Klimpfinger $M$, et al. (2005) Prognostic significance of tumor regression after preoperative chemoradiotherapy for rectal cancer. J Clin Oncol 23(34): 8688-9610.

8. Shia J, Guillem JG, Moore HG, Tickoo SK, Qin J, et al. (2014) Patterns of morphologic alteration in residual rectal carcinoma following preoperative chemoradiation and their association with long-term outcome. Am J Surg Pathol 28: 215, 2004-2223. 
9. Wheeler JM, Warren BF, Mortensen NJ (1999) Quantification of histologic regression of rectal cancer after irradiation: A proposal for a modified staging system. Dis Colon Rectum 45: 2002-1056.

10. Shia J, McManus M, Guillem JG, Leibold T, Zhou Q et al. (2011) Significance of acellular mucin pools in rectal carcinoma after neoadjuvant chemoradiotherapy. Am J Surg Pathol 35(1): 127-134.

11. Märkl B, Schaller T, Krammer I, Cacchi C, Arnholdt HM, et al. (2013) Methylene blue-assisted lymph node dissection technique is not associated with an increased detection of lymph node metastases in colorectal cancer. Mod Pathol 26(9): 1246-1254.
12. Jass JR, O Brien J, Riddell RH, Snover DC (2008) Association of Directors of Anatomic and Surgical Pathology. Recommendations for the reporting of surgically resected specimens of colorectal carcinoma: Association of Directors of Anatomic and Surgical Pathology 129(1): 13-23.

13. Benson AB 3rd, Bekaii-Saab T, Chan E, Chen YJ, Choti MA, et al. (2012) Rectal cancer. J Natl Compr Canc Netw 10(12): 1528-1564.

14. Gehoff A, Basten O, Sprenger T, Conradi LC, Bismarck C, et al. (2012) Optimal lymph node harvest in rectal cancer (UICC stages II and III) after preoperative 5-FU-based radiochemotherapy. Acetone compression is a new and highly efficient method. Am J Surg Pathol 36 (2): 202-213.

\section{(C) $(9)$ This work is licensed under Creative}

To Submit Your Article Click Here:

Submit Article

DOI: $10.32474 /$ LOJMS.2018.01.000102

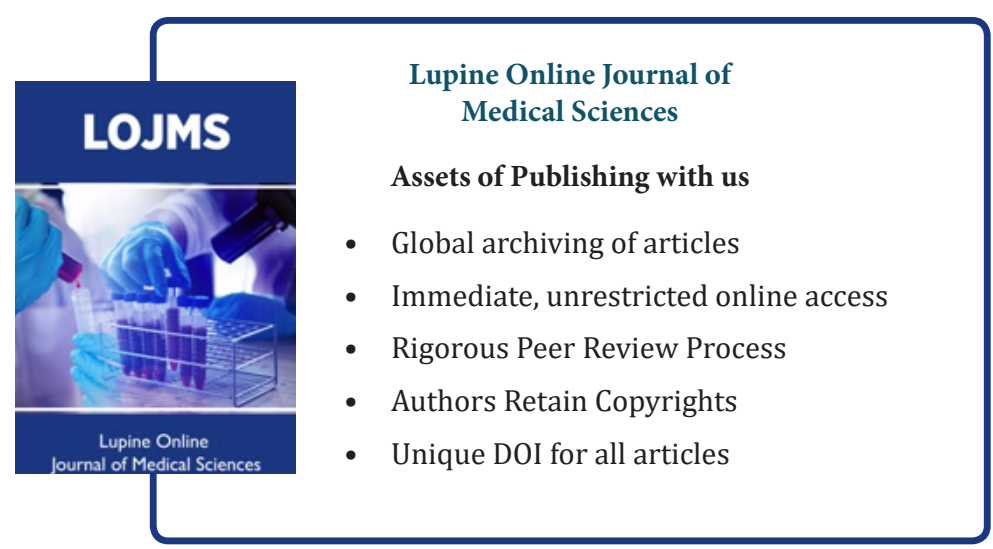

